\title{
Increasing the energy conversion efficiency for shrouded hydrokinetic turbines using experimental analysis on a scale model
}

\author{
Rareș-Andrei Chihaia ${ }^{1,{ }^{*}}$, Lucia-Andreea El-Leathey ${ }^{1}$, Gabriela Cîrciumaru$^{1}$, and Nicolae Tănase ${ }^{1}$ \\ ${ }^{1}$ National Institute for Research \& Development in Electrical Engineering ICPE-CA, Splaiul Unirii 313, Bucharest, Romania
}

\begin{abstract}
The objective of the paper is to study the influence of certain shroud types suitable for horizontal axis hydrokinetic turbines using experimental testing in order to increase the energy conversion efficiency. The scale model of the shrouded hydrokinetic turbine is tested on a dedicated experimental bench for axial hydraulic turbine models. Two types of shrouds were tested in order to be compared: convergent shroud and divergent shroud. The rotor and shroud were made using 3D printer technology and were tested at a water velocity of $0.9 \mathrm{~m} / \mathrm{s}$ on the closed-circuit testing bench. The testing facility allows the determination of the power extracted for each shroud at five distinct positions. Thus, the rotor can be moved within the shroud from inlet to outlet in order to establish the proper operating position. The mechanical power is measured using a torque transducer and an electromagnetic particle brake. The testing results will be analysed based on the variation of power curves obtained for different shroud types and operating positions. The optimum design and the best operating position will be recommended by comparing the testing result with the data collected from the bare turbine using the same rotor placed directly in free flow.
\end{abstract}

\section{Introduction}

In order to avoid building a dam, the kinetic energy of a river can be used directly using hydrokinetic turbines. This type of turbine has a simple design, is easy to install with reduced cost and low-maintenance. The current velocity of $1 \mathrm{~m} / \mathrm{s}$ has a theoretical energy density of 500 $\mathrm{W} / \mathrm{m}^{2}$ in cross-section but only a part of this energy can be extracted and converted to useful mechanical energy.

The power coefficient $(\mathrm{Cp})$ and multiple factors affect the power output of such run-of-the river devices. In terms of the turbine design, the conversion performance is mainly related to the rotor and blade type.

The water velocity is important because the power output varies with the velocity at third power. Nowadays, there are various conceptual solutions, but yields are relatively low. Therefore, the issue of increasing the efficiency of converting the kinetic energy of water remains a topic of high interest, which was always in the focus of the researchers worldwide [1],[2],[3].Conventional solutions are continuously improved and new solutions are emerging that offer higher yields. For a given water flow rate, the power coefficient may not exceed the theoretical maximum value of 0.59 provided by the Betz limit. The only way to increase the power extracted at the same flow rate remains the use of shrouds of different shapes, sections and opening angles.
Bare kinetic turbines extract energy from the stream by reducing the flow rate locally without a significant pressure reduction in the rotor area. Instead, in a diffuser augmented turbine, the extracted energy is mainly due to local pressure drops, and the kinetic rotor will act as a very low drop hydraulic turbine. Thus, the maximum output power can be determined as the product between the flow and the head expressed by the pressure difference. The radial flow of the fluid around the blades is not possible when shroud is used, thus it allows yields up to $90 \%$, similar to those for conventional hydraulic turbines.

The role of the shroud is to increase the extracted power by increasing the mass flow through the rotor. Shrouds used for hydrokinetic turbine can be classified mainly into two broad categories: convergent shroud and divergent shroud (diffuser).

The pressure drop available for a shrouded turbine depends on the shape of the shroud and the flow through it and around it. If the shroud is designed as a diffuser, then the turbine will attract more fluid and will benefit from a pressure drop. This results in a "diffuseraugmented" turbine [4].

Although an increase of the power coefficient can be observed when using diffuser-augmented turbine, Van Bussel warns that no experiments on ducted turbine have ever led to power coefficient larger than 0.47 when referred to the properly chosen reference area [5]. The Betz limit applies for both shrouded and bare turbines when referring to the swept area exposed to the flow.

\footnotetext{
* Corresponding author: rares.chihaia@icpe-ca.ro
} 
When the $\mathrm{Cp}$ of a shrouded turbine is calculated using the rotor swept area, the $\mathrm{Cp}$ should be referred as rotor power coefficient. Only for this approach, the $\mathrm{Cp}$ value can exceed the Betz limit. If the $\mathrm{Cp}$ is calculated for the swept area of the whole turbine, then its value decreases due to the fact that the reference area used for determining the theoretical power is larger. Some authors prefer using $\mathrm{Cp}$ calculated for the whole turbine and others refer only to the rotor $\mathrm{Cp}[6]$.

In this paper, the power coefficient determined for the experimental model of shrouded turbine is calculated as $\mathrm{Cp}$ of the rotor. Despite the many advantages in term of energy conversion, the only problem is that the shrouds have large exposed surfaces, which complicates the constructive solution by the fact that the stresses and strains are relatively high. By improving the operation of such hydrokinetic turbines, their implementation will become feasible and can be taken into account for widespread use.

\section{Testing methodology}

Analyzing from the multitude of currently available shroud solutions, two types with the best results were chosen for designing and fabrication using a 3D printer: convergent shroud and divergent shroud. The same shroud was used in two versions: - diffuser (divergent shroud), when the turbine will attract more fluid and will also benefit from a pressure drop downstream[4].

- convergent shroud with good results due to the fact that the upstream section of the rotor is increased. This results in a concentration of the flow that will in turn increase the local velocity in the rotor area.

The shroud was tested with a $200 \mathrm{~mm}$ diameter rotor. Considering the testing bench channel of $300 \mathrm{~mm} \times 300$ $\mathrm{mm}$, a maximum shroud diameter of $250 \mathrm{~mm}$ is chosen. This results in an area of $49.087 \mathrm{~mm}^{2}$ exposed to flow, sufficient to avoid the risk of spillage when testing at high velocity. A cylindrical duct to smooth the flow around the rotor was used. The gap between the cylindrical duct and rotor was kept at $3 \mathrm{~mm}$ to ensure a sufficient distance between the two surfaces. The cylindrical support has an internal diameter of $206 \mathrm{~mm}$ and a length of $70 \mathrm{~mm}$. According to the recommendations of the literature, the opening angle is $25^{\circ}$, resulting in a length for the divergent shroud of 47 $\mathrm{mm}$. The entire shroud assembly will be $117 \mathrm{~mm}$ long.

The experimental model of the shroud shown in Fig.1 was made from ABS plastic material which is strong enough for the desired application, having a tear strength of $36 \mathrm{MPa}$. The convergent/divergent shroud made of ABS was then embedded in a stainless steel roller for mechanical stiffening. For fastening and aligning the shroud around the $200 \mathrm{~mm}$ rotor, a stainless steel bar with a diameter of $10 \mathrm{~mm}$ was used to connect with a fastening and adjustment system.

Testing of the experimental model of the shrouded kinetic turbines was done on a test stand designed specifically to experiment with kinetic turbines scale models.
The closed-circuit hydraulic stand has a transparent viewing section of $375 \times 300 \times 1015 \mathrm{~mm}$, and adjustable water velocity in the range of $0,05 \mathrm{~m} / \mathrm{s}-1 \mathrm{~m} / \mathrm{s}$. For the conducted experiments it was selected the reference water velocity of $0,9 \mathrm{~m} / \mathrm{s}$ both to compare the results with those obtained for the $500 \mathrm{~mm}$ prototype rotor, from which the optimization process was started and also to estimate the predictive performance curves, for other rotors at $0,9 \mathrm{~m} / \mathrm{s}$.

The velocity in the channel was measured in several points upstream of the rotor using a Pitot tube connected to a differential pressure sensor which transmits the data to a central unit for data acquisition and storage. By loading the electromagnetic particle brake, the power output could be extracted using a torque transducer that also measured the rotational speed. The shroud for the experimental model rotor was centered using a specially designed sliding device. The measurement system is described in Fig.1.

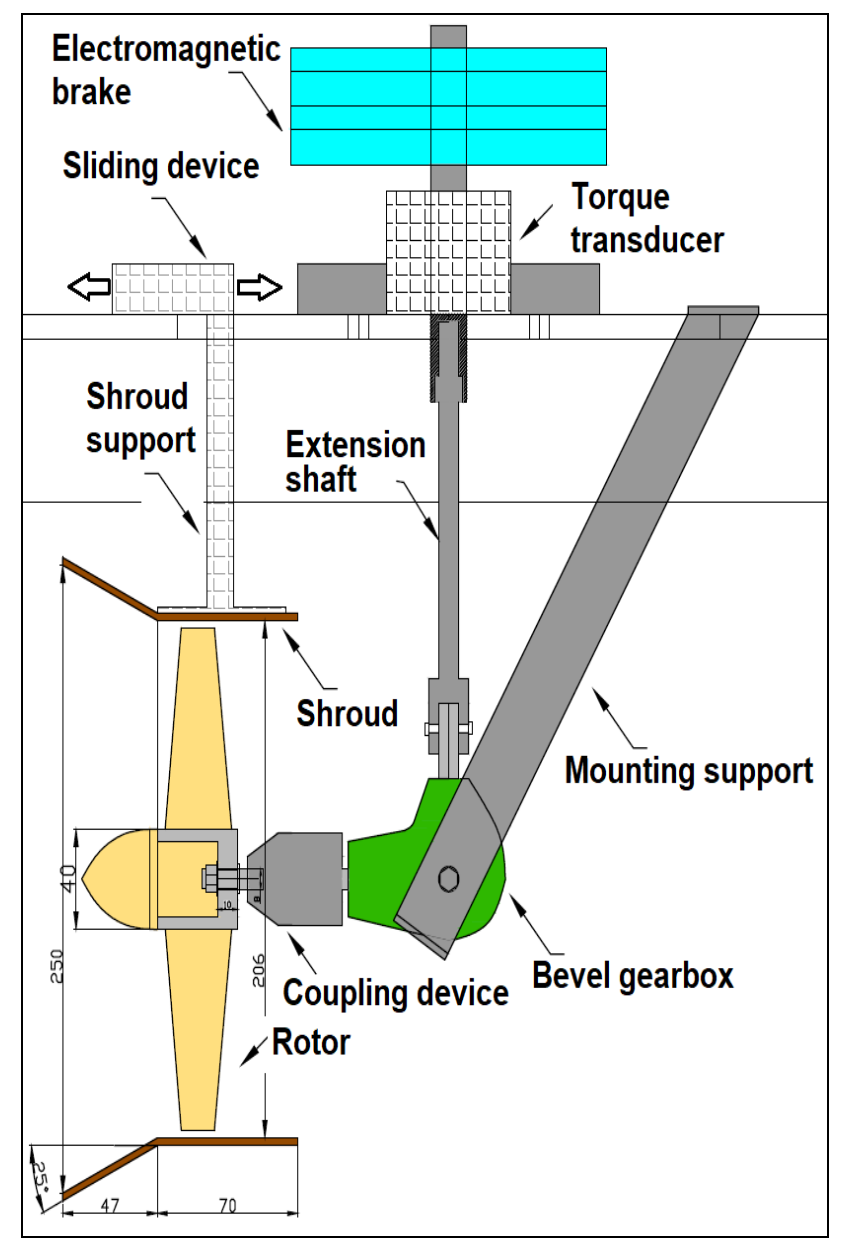

Fig.1. Measurement systems and main components.

This system allows performing the necessary tests by changing the position relative to upstream or downstream of the rotor in order to establish the measurement points 1 to 5 for the convergent/divergent shroud. Each selected position is aligned with the midpoint of the rotor blade with a pitch angle of $40^{\circ}$ for which experimental results are known [7]. Figure 2 shows the rotor-shroud assembly and the measuring positions marked from 1 to 5 . 


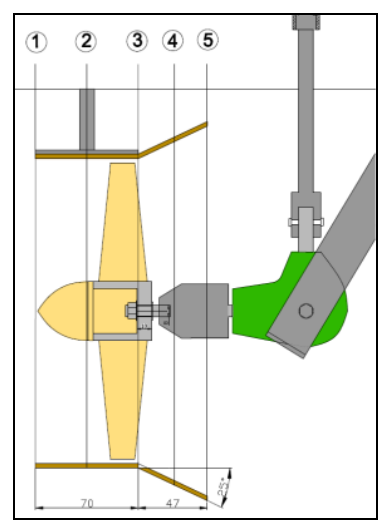

Fig.2a. Divergent shroud.

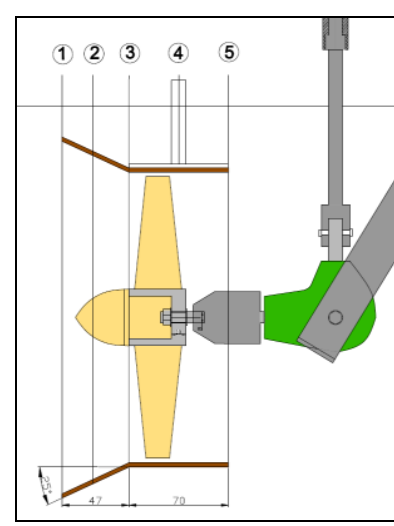

Fig.2b. Convergent shroud.
In fig $2 \mathrm{a}$ is shown the divergent shroud and in fig. $2 \mathrm{~b}$ is shown the convergent shroud. The characteristic sections of the measure were chosen as follows:

\section{a. For divergent shroud (Figure 2a):}

- Position 1 - Edge of the cylindrical duct - upstream;

- Position 2 - Midpoint of the cylindrical duct (35mm from position 1 ),

- Position 3 - End of the cylindrical duct (at 70mm from position 1);

- Position 4 - Midpoint of the divergent shroud (at 95mm from position 1);

- Position 5 - Edge of the shroud - downstream (at 117 $\mathrm{mm}$ from position 1);

\section{b. For convergent shroud (Figure 2b):}

- Position 1 - Peripheral of shroud - upstream; - Position 2 - Half of convergent shroud (at 22mm from position 1);

- Position 3 - End of convergent shroud (at 47mm from position 1);

- Position 4 - Half of the cylindrical duct (82mm from position 1).

- Position 5 - Peripheral of shroud - downstream (at 117 mm from position 1);

The characteristic sections were chosen at key points along the shroud in order to study the shroud effect upon the rotor. The distance between the measuring points ensures a sufficient variation of rotor speed and torque which allows distinctive curves for each operating positions.

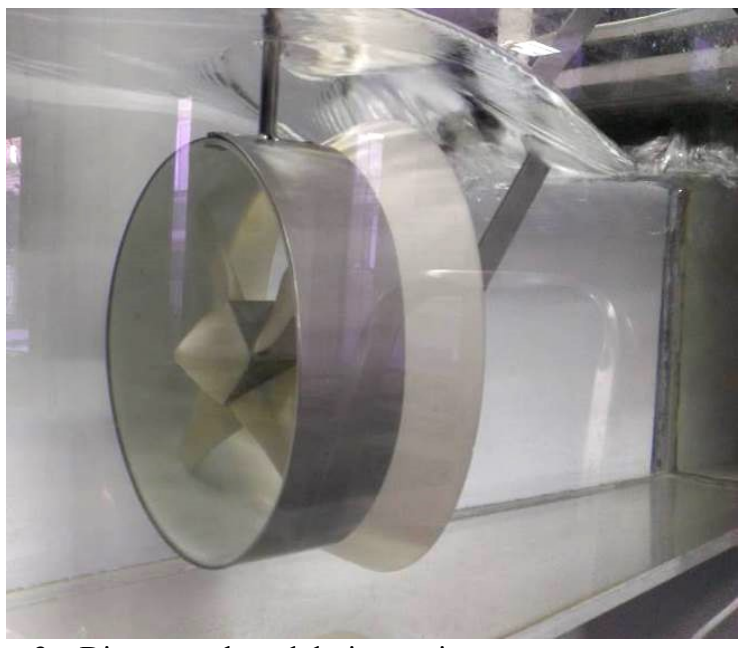

Fig. 3a. Divergent shroud during testing.

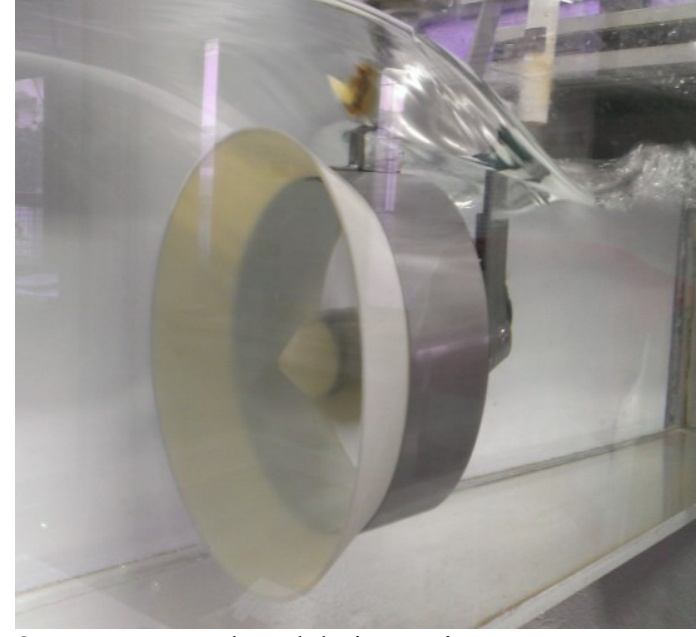

Fig. 3b. Convergent shroud during testing.

In figures $3 \mathrm{a}$ and $3 \mathrm{~b}$, the shrouded turbine during testing is presented. All tests were performed at $0.9 \mathrm{~m} / \mathrm{s}$ for a maximum admissible water depth of $30 \mathrm{~cm}$ to minimize the influence of the free surface and the turbulence that can be formed at high water velocities $(0.9-1 \mathrm{~m} / \mathrm{s})$ [7]. Thus, the free surface level is $30 \mathrm{~cm}$, with some variations in downstream flow depending on the rotor speed.

\section{Findings and results interpretation}

The aim of the experiments was to determine the characteristic parameters for the tested rotors that allow plotting the power coefficient and power curve as $\mathrm{Cp}=\mathrm{f}$ $(\lambda), P=\mathrm{f}(n)$ graphs. These curves allow the evaluation of the hydrokinetic turbine efficiency. The main recorded parameters are the useful torque at the turbine shaft and rotational speed of the shaft recorded at the same water velocity. Based on these parameters the useful power can be determined with the formula:

$$
P=M \omega
$$

where $M-$ is the torque, and $\omega$ represents the angular speed, which can be determined as:

$$
\omega=2 \pi n / 60
$$

where $n$ - represents the rotational speed of the rotor.

With these calculated values, the curves $P=f(n)$ can be determined. Another important characteristic curve for describing the operation of a hydrokinetic turbine is that of the power coefficient - Cp in relation to $\lambda$ (TSR Tip Speed Ratio) - which is the ratio of the peripheral velocity to the considered fluid velocity. To determine the $\mathrm{Cp}=\mathrm{f}(\lambda)$ curve, it is necessary to determine $\lambda$ by the following formula:

$$
\lambda=V_{\text {perif. }} / v
$$

where $\mathrm{V}_{\text {perif. }}$ - represents the rotation speed at the periphery of the rotor and $v$ - mean water velocity upstream that can be determined as follows:

$$
V_{\text {perif }}=\omega R
$$


where $\mathrm{R}$ is the radius of the rotor under test. Also, a very important parameter is the power coefficient - $C p$ because its value defines the kinetic turbine yield, more specific how much energy can be obtained from a water stream, by reference to the theoretical power. It can be calculated with the following formula:

$$
P_{\text {th. }}=\frac{1}{2} \rho A v^{3}
$$

The rotor power coefficient can be determined as:

$$
C_{p}=\frac{P}{P_{t h .}}=P / \frac{1}{2} \rho A v^{3}
$$

where $\mathrm{A}-$ is the exposed area of the rotor and $\rho$ - water density.

Using the above formulae, the characteristic curves for each tested shroud can be plotted. For the divergent shroud shown in Figure 2a and its characteristic positions, the curves $\mathrm{P}=\mathrm{f}(\mathrm{n})$ are presented in Fig.4

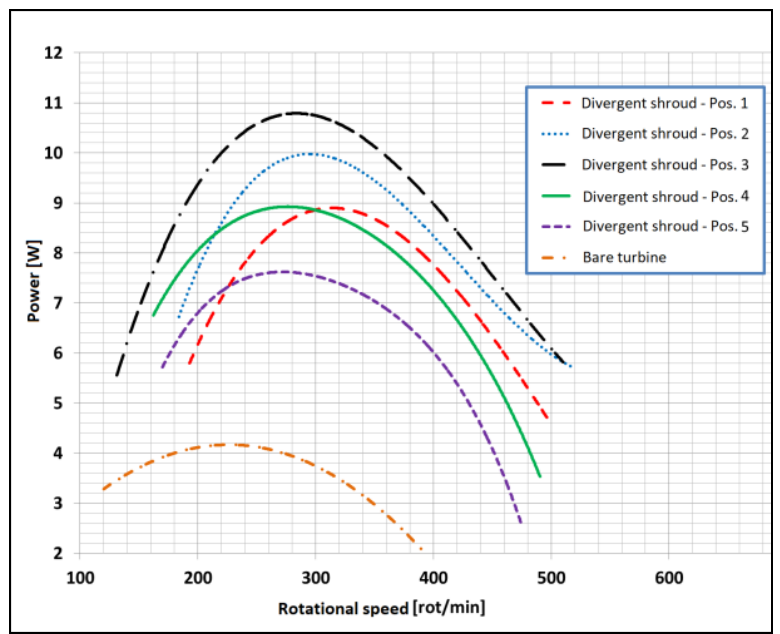

Fig.4. Power variation depending on the rotational speed for the divergent shroud.

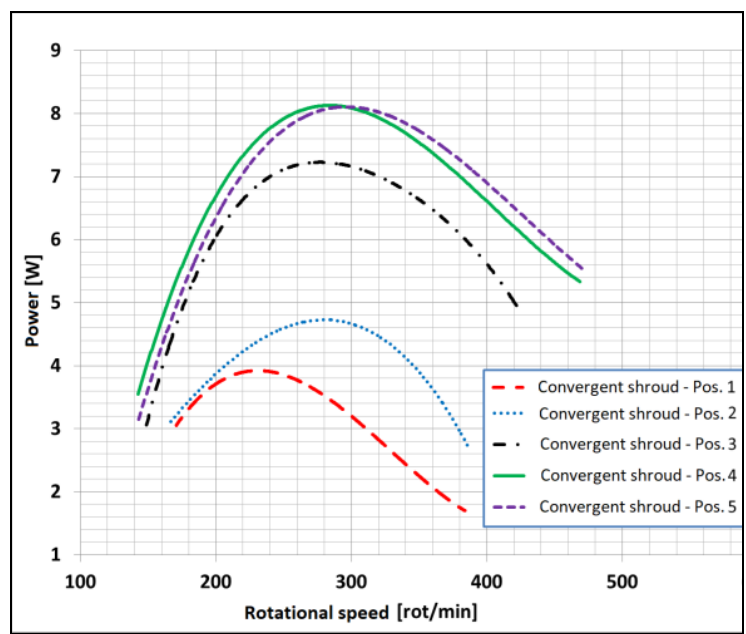

Fig.5. Power variation depending on the rotational speed for the convergent shroud.

The divergent shroud arrangement generates a power output of up to $11 \mathrm{~W}$ at a speed of $300 \mathrm{rpm}$ for position 3 .
This position is situated in the region of the edge between the cylindrical duct and the divergent shroud.

The increase in extracted power is due to the fact that the divergent shaped shroud contributes to lowering pressure at the turbine outlet and thereby accelerating the flow through the turbine [9].

Thus, if the rotor is placed before the divergent shroud (position 3), then the speed through it increases given the above mentioned effect. There is an increase in power of up to 2.6 times in this case compared to the bare rotor which generates about $4 \mathrm{~W}$.

For the convergent shroud shown in Figure $2 b$ and its characteristic positions, the curves $\mathrm{P}=\mathrm{f}(\mathrm{n})$ are presented in Fig.5

It can be observed that the maximum power output is about $8 \mathrm{~W}$ at a speed of $300 \mathrm{rpm}$ for positions 4 and 5 located at the midpoint of the cylindrical duct and respectively on the shroud downstream edge, as shown in Fig. 2b. The other characteristic positions have not produced better results due to the low influence of the shroud towards the flow. It is worth mentioning that for the first position, the extracted power is similar to the bare turbine, namely around $4 \mathrm{~W}$. It therefore, results that the use of this type of shroud induces an increase in power up to $100 \%$ from 4 to $8 \mathrm{~W}$.

In the following diagrams, the $\mathrm{Cp}=\mathrm{f}(\lambda)$ characteristic curves for each shroud at different positions are presented. These diagrams are useful because they present an overview of the energy conversion efficiency and can be used to predict the power provided by other shrouded rotors on a larger scale based on the prediction curves obtained by adapting the $\mathrm{Cp}=\mathrm{f}(\lambda)$ graphs, as shown in [7].

In Fig. 6 and Fig.7, the curves $\mathrm{Cp}=\mathrm{f}(\lambda)$ for the divergent and convergent shrouds are shown.

Given the maximum shroud diameter of $250 \mathrm{~mm}$ is close to the channel dimensions of $300 \mathrm{~mm} \times 300 \mathrm{~mm}$, blockage effect occurs and can be observed in Fig.3a and $3 b$. Placing a turbine in a wind or water tunnel partially blocks the flow passage of the channel test section. This increases the flow velocity upstream of the turbine which increases the measured torque and thrust. Therefore, turbine performance obtained in a partially blocked flow needs correction to represent performance of the turbine in an unbounded free stream [10].

To identify equivalent open water operating conditions, the principle adopted is to calculate an equivalent water speed as free stream velocity $-V_{f}$. Thus, the ratio between the mean water velocity in the testing channel $-v$ could be written as [8]:

$$
\frac{v}{V_{f}}=\frac{V_{r} / v}{\left(V_{r} / v\right)^{2}+C_{t d} / 4}
$$

where $V r$ - represent the velocity just behind the rotor and $C_{t d}$ - represent the thrust coefficient for rotor placed inside a divergent shroud.

$$
C_{t d}=\beta \gamma 4 a(1-a)
$$

where $\beta$ represent the divergent shroud area ratio, $\gamma$ represent the back pressure velocity ratio and $a$ is the 
axial induction factor that can be determined at different $C p$ values using this relation:

$$
C_{p}=4 a(1-a)^{2}
$$

Determining the the $v / V f$ ratio allows the correction for $\mathrm{Cp}$ and $\lambda$ as follows:

$$
\begin{gathered}
C_{p}=C_{p C}\left(\frac{v}{V_{f}}\right)^{3} \\
\lambda=\lambda_{C}\left(\frac{v}{V_{f}}\right)
\end{gathered}
$$

where $\mathrm{C}_{\mathrm{pC}}$ and $\lambda_{\mathrm{c}}$ represent the values obtained using the experimental data before the correction due to blockage effect. Applying the relations above, some corrections were applied ranging from 5 and $20 \%$ for the power coefficient and tip speed ratio in order to account for the blockage effect.

Nevertheless, the testing results clearly show also that the divergent shroud has better performances in terms of power coefficient. These types of curves are useful for comparing with the efficiency obtained by other types of turbines by highlighting the power coefficient depending on the TSR (how much power is available to extract from a water stream depending on the peripheral speed of rotation).

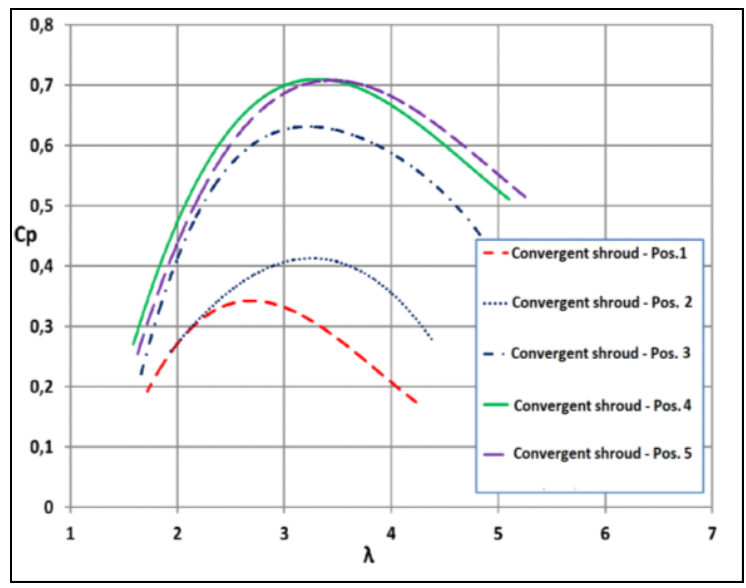

Fig.6. Power coefficient variation for convergent shroud.

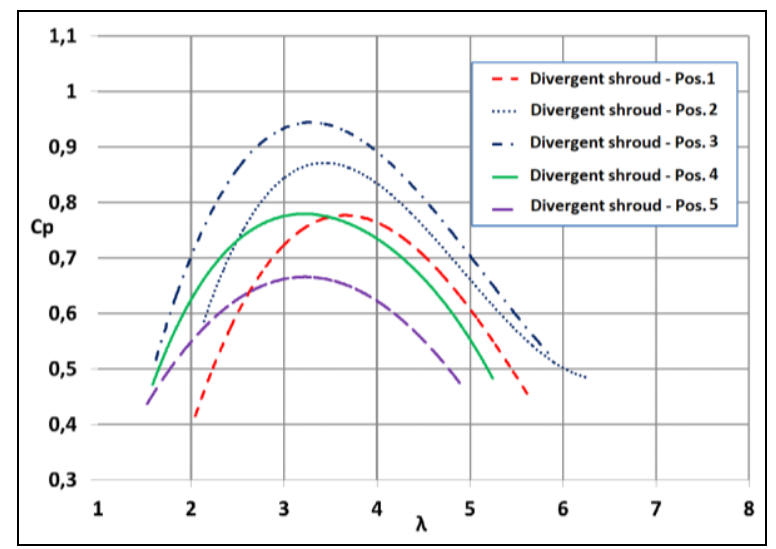

Fig.7. Power coefficient variation for divergent shroud.

\section{Power estimation for small hydrokinetic turbines}

The mechanical power obtained at the shaft of the experimental model of the kinetic turbine is relatively small. The use of shrouds around the rotor can double the output power. Therefore, a shrouded kinetic turbine similar to the one studied in this project can find utility in various applications requiring low power consumption (data signalling, transmission and reception, monitoring and parameter storage).

The water flow velocity of $0.9 \mathrm{~m} / \mathrm{s}$ is not specific to most rivers but is more likely to be identified in certain areas of the Danube. It is therefore important to study if such a turbine is suitable for rivers with a reduced flow rates.

In this respect, with best-fit shroud, the experimental model of the turbine was tested at lower flow rates in order to demonstrate its applicability to low-flow rivers or channels. The results were synthesized in Fig.8.

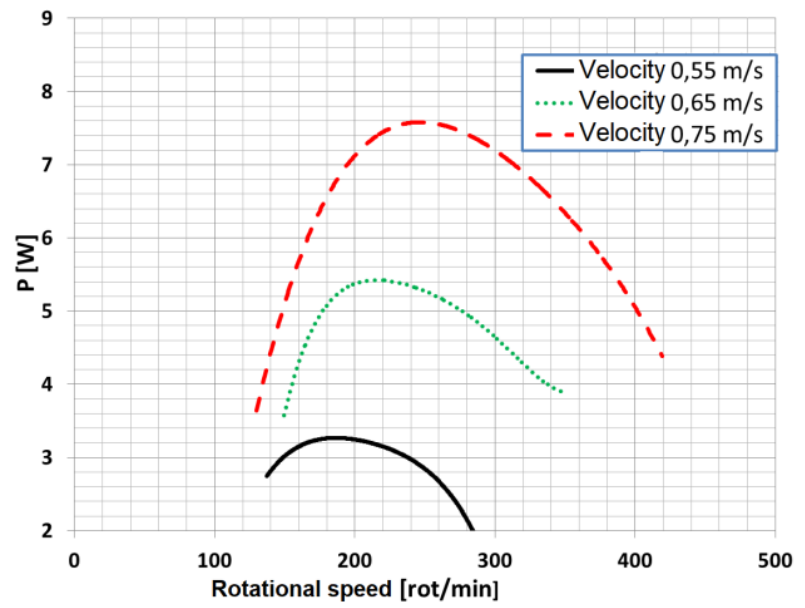

Fig.8. Power curves for hydrokinetic turbine with best-fit shroud at $0,55-0,75 \mathrm{~m} / \mathrm{s}$ velocity.

It results from the diagram in Figure 8 that the intubated kinetic turbine can supply over $5 \mathrm{~W}$ at water velocities of $0.65 \mathrm{~m} / \mathrm{s}$ which are much more common on rivers or channels than the $0.9 \mathrm{~m} / \mathrm{s}$ velocity. The power provided is not high, especially if we take into account the losses of an electric generator. However, due to the fact that the energy efficiency of consumer electronics has decreased over time, even a power of only $5 \mathrm{~W}$ can be useful under certain circumstances.

For example, some electrical consumers can be recommended for use:

- data logger for data acquisition from different sensors and remote transmission via GPRS, router, ADSL modem etc;

- telephone, laptop, portable radio/tv, various lowpower equipment with a battery charging controller;

- LED bulb lighting (a $5 \mathrm{~W}$ bulb provides a $4701 \mathrm{~m}$ (equivalent to $40 \mathrm{~W}$ - incandescent bulb).

Thus, this small hydrokinetic turbine could be used as a reliable power supply in remote areas with access to a stream nearby. If the water velocity cannot be increased, then a higher rotor diameter will be needed to supply the necessary power. 
In this regard, it is necessary to use calculation techniques that predict the power level generated by a particular rotor of a hydro-kinetic turbine with a certain size. According to some of the literature recommendations, it is possible to adapt the power coefficient $(\mathrm{Cp})$ vs. Tip Speed Ratio $(\lambda)$ curve in order to achieve estimations using experimental rotor model [11].

Thus, assuming the same diagram for other large diameters, it can be possible to predict the output power for certain hydrokinetic rotors on a close scale [11]. Using the power coefficient, the mechanical power extracted at a certain rotational speed can be determined.

Hence, a power curve (Fig.6 or Fig.7) for another rotor with larger diameter can be drawn, by keeping the same design and flow condition (water velocity $0.9 \mathrm{~m} / \mathrm{s}$ ).

\section{Conclusion}

The conducted research is consistent with the trends identified in literature and was aimed to study the influence of certain shroud types suitable for horizontal axis hydrokinetic turbines using experimental testing methods. Two types of shrouds were tested in order to be compared: convergent shroud and divergent shroud (diffuser). The rotor and shrouds were made using 3D printer technology and were tested at a water velocity of $0.9 \mathrm{~m} / \mathrm{s}$ on the closed-circuit testing bench.

The testing facility allows the determination of the power extracted for each shroud at five distinct positions. Thus, the rotor can be moved inside the shroud from inlet to outlet in order to establish the proper operating position.

The best results were obtained using the divergent shroud with the rotor placed in front of the shroud, aligned with the upstream edge.

The topic of the paper addresses the sustainable and renewable energy sources domain, in the context of the depletion of conventional energy sources and the pressing need to produce electricity from renewable sources. The results obtained in terms of power extracted and efficiency for experimental scale models can be extrapolated to determine the power delivered by a larger scale power generation installation.

This work was financially supported by the following grants of the Romanian Ministry of Research and Innovation (MCI): CCCDI-UEFISCDI, project number PN-III-P1-1.2-PCCDI2017-0391 / CIA_CLIM - Smart buildings adaptable to the climate change effects and also by NUCLEU 2018 Programme, project number PN18240201/ 2018 - Efficient energy conversion and storage systems for electrical engineering applications.

\section{References}

1. M.J. Khan, M.T. Iqbal, J.E. Quaicoe, Renewable and sustainable energy reviews, Vol. 12, Issue 8, Pages 2177-2193 (2008);

2. Veronica B. Miller, Emmanuel W. Ramde, Robert T. Gradoville Jr., Laura A. Schaefer, Renewable Energy 36 pg. 671-675, (2011);
3. Rudi Henri van Elsa, Antonio Cesar Pinho, Energy Procedia no.75, pg.259 - 264; (2015);

4. B. Kirke, Tidal paper 3-6, 25-04-06, (2005);

5. G.Van Bussel, Journal of Physics: Conference Series 75 (2007) 012010;

6. C.Belloni, Hydrodynamics of Ducted and OpenCentre Tidal Turbines, Doctorat Thesis, Oxford 2013

7. R.A. Chihaia, F. Bunea, G. Oprina, L.A. El-Leathey, CIEM, pp. 221-225. (2017);

8. Bahaj, A. Molland, J. Chaplin and W. Batten, Renewable Energy, 32(3), pp. 407 - 426. (2007).

9. L.A. Gish, G.Hawbaker, Experimental and numerical study on performance of shrouded hydrokinetic turbines, OCEANS 2016 MTS/IEEE Monterey, pp. $1-5$

10. M. Shahsavarifard, E.L. Bibeau, V.Chatoorgoon, Ocean Engineering, Volume 96, (2015), Pg. 215-225

11. Javaherchi Teymour,Seydel Joseph, Stelzenmuller Nick, Aliseda Alberto, Experimental and Numerical Analysis of a Scale-Model Horizontal Axis Hydrokinetic Turbine, Proceedings of the 2nd Marine Energy Technology Symposium METS2014, April 15-18, 2014, Seattle, WA. 